\title{
(JIPD)
}

Jurnal Inovasi Pendidikan Dasar

Vol. 4, No. 2, Bulan Juli Tahun 2020, Hal. 71-75

E-ISSN: 2598-408X, P-ISSN: 2541-0202

http://unikastpaulus.ac.id/jurnal/index.php/jipd

https://doi.org/10.36928/jipd.v4i2.354

\section{URGENSI PENDIDIKAN MULTIKULTURAL: SEBUAH JAWABAN ATAS PROBLEMATIKA PLURALITAS}

\author{
Gregorius We'u \\ Universitas Flores, Ende, Nusa Tenggara Timur
}

Diterima: 11 Januari 2020, Direvisi: 15 Mei 2020, Diterbitkan: 15 Juli 2020

\begin{abstract}
Plurality or pluralism is a real situation that must be accepted by all Indonesian people who are built on the basis of differences. These differences at some point can create conflict. Therefore, a solution or prevention is needed, namely multicultural education, so that plurality or pluralism can be maintained and accepted as an asset or wealth owned by the Indonesian nation. The aim is to maintain national harmonization and integration. The research method used is descriptive qualitative research method with reference to Milles and Huberman theory. Thus, the results obtained that multicultural education is problem solving in the midst of plurality or pluralism, which increasingly leads to something negative or fanaticism in various aspects or dimensions. The conclusion is plurality or pluralism is a social fact that must be accepted consciously and critically in order to create the condition of Indonesian human beings who are respectful, respectful, peaceful, secure, orderly, and share each other in order to improve the sovereign, fair and prosperous dignity of the nation and civilized.
\end{abstract}

Keywords: Plurality, conflict, and multicultural education

\begin{abstract}
Abstrak: Pluralitas atau kemajemukan merupakan sebuah situasi riil yang mesti diterima oleh semua masyarakat Indonesia yang dibangun atas dasar perdebedaan-perbedaan.Perbedaan-perbedaan itu pada suatu titik tertentu dapat menciptakan konflik.Oleh karena itu, diperlukan sebuah solusi atau pencegahannya yakni pendidikan multikultural, agar pluralitas atau kemajemukan dapat dipertahankan dan diterima sebagai sebuah aset atau kekayaan yang dimiliki oleh bangsa Indonesia.Tujuan adalah untuk mempertahnakan harmonisasi dan integrasi bangsa.Metode penelitian yang digunakan adalah metode penelitian kualitatif deskriptif dengan mengacu pada teori Milles dan Huberman.Sehingga, hasil yang diperoleh bahwa pendidikan multikultural merupakan problem solving di tengah pluralitas atau kemajemukan, yang semakin mengarah kepada sesuatu yang negatif atau sikap fanatisme dalam berbagai aspek atau dimensi. Kesimpulannya adalah pluralitas atau kemajemukan merupakan fakta sosial yang mesti diterima secara sadar dan kritis agar terciptanya kondisi manusia Indonesia yang saling menghargai, saling menghormati, damai, aman, tertib, dan saling berbagi dalam rangka meningkatkan harkat dan martabat bangsa yang berdaulat, adil, makmur dan beradab.
\end{abstract}

Kata Kunci: Pluralitas, konflik, dan pendidikan multikultural

\section{PENDAHULUAN}

Bangsa Indonesia adalah bangsa yang plural.Disebut sebagai bangsa yang plural karena bangsa ini disatukan oleh perbedaanperbedaan.Perbedaan itu nampak dalam hal agama, suku, bahasa daerah, ras, taraf hidup, tingkat pendidikan, dan antar golongan atau stratifikasi sosial.Statement ini menjelaskan fungsi strategis dari peran foundingfathersand mothers sebagai pendiri bangsa ini dalam mempersatukan dimensi kepluralitasan.Artinya, menggagaskan kesatuan dan mewujudkan aksi bukanlan merupakan sesuatu yang tidak sulit. Namun spirit untuk move on yang meyakinkan diri untuk mampu keluar dari situasi pelik, situasi terjepit, situasi tanpa ada hak, dan juga di dalamnya ada situasi ambang batas.

Situasi ambang batas adalah situasi berakhirnya politik devide et impera dan muncul lighting baru untuk membuka kehidupan baru, sebuah kehidupan yang bebas dari jajahan 
kolonial, dan akan terwujudnya kebebasan baru untuk secara bijak menentukan nasib hidup sendiri sebagai orang Indonesia. Kebebasan baru yang dimaksudkan adalah sebuah hak atau mendapat pengakuan dari orang lain atau bangsa lain yang di dalamnya terkandung usaha untuk membentuk Negara kesatuan Republik Indonesia (NKRI) yang aman, damai, mendapat perlakuan yang adil, hak berorganisasi, dan tanpa adanya penjajah atau situasi merdeka.

Kemerdekaan adalah sebuah rahmat atau anugerah dari Sang Empunya Kehidupan ini atau yang dalam agama disebut dengan nama Tuhan. Tuhan yang menghadiakan kemerdekaan kepada suatu bangsa tertentu berkat perjuangan untuk segera berakhirnya situasi dalam katupan tangan penjajah.Oleh karena itu, kemerdekaaan perlu dipertahankan dan dikembangkan dalam prestasiprestasi kerja anak bangsa.Untuk dapat meraih prestasi maka harus bekerja keras dan membangun relasi dengan banyak orang.Hal ini berarti bahwa menjujung tinggi semangat persaudaraan, menjaga persatuan dan kesatuan bangsa, mewujudkan perdamaian yang abadi. Itulah indahnya ketika hidup dan ada bersama dengan yang lain, karena pada dasarnya manusia adalah makluk sosial yang tidak dapat hidup dari dirinya sendiri. Sehingga perlu menerima kehadiran yang lainyang berarti siap untuk menerima kemajemukanataupluralitas.

Kepluralitasan adalah aset atau harta yang dimiliki oleh bangsa, yang mesti terus dihargai dan dijunjung tinggi sehingga tidak perlu dipersoalkan atau secara lebih gamblang dan berani dikatakan adalah pluralitas tidak perlu menjadi masalah. Namun realitanya berkata lain, banyak masalah yang terjadi disebabkan oleh pluralitas. Artinya, pluralitas selain menyatukan tetapi pada sisi lain bahwa pluralitas dapat menciptakan konflik dan konflik merupakan ekspresi dari keakuan yang superior, sikap primordialisme, fanatisme dalam pelbagai dimensi yang menyebabkan situasi survive menjadi chaos. Situasi chaos memberi arti bahwa ada pengetahuan yang minim, dan pemahaman yang rendah terhadap cikal bakal NKRI dibentuk

Konflik horisontal, misalnya pernah terjadi da Sampit, Banyuwangi, Tasikmalaya, Lampung, Jakarta, Kupang, Ambon, Sambas, dan beberapa daerah di Indonesia lainnya (Jurahman, 2014:79). Pernyataan tersebut juga didukung oleh hasil penelitian yang dilakukan oleh Achmad Habib, yang mengambil tema: konflik antar etnik di pedasaan, pasang surut Hubungan Cina-Jawa, menggunakan konstruksi sosial sebagai perspektif teori. Temuannya menyebutkan bahwa muncul konflik antar etnik dipengaruhi oleh posisi sosial yang berbeda di mana dalam hal perekonomian, Cina lebih berperan sebagai majikan sedangkan etnik Jawa sebagai buruh (Sulalah, 2011: 30-31).

Konflik disebabkan pula oleh sikap eksklusivitas para pemimpin dan penganut suatu agama (Arifin Assegaf dalam Sumartanadkk, 2001: 34). Artinya, dengan menanamkan eksklusivisme maka timbul sikap fanatisme yang akan menciptakan jurang pemisah dengan sikap responsif dialogis terhadap agama ataupun pasa aspek-aspek yang lain.

\section{PENDIDIKAN MULTIKULTURAL \\ Konsep}

Konsep pendidikan multikultural menurut Mundzier Suparta dalam (Ibrahim, 2013) mengemukakan beberapa konsep tentang pendidikan multikultural:

1. Bahwa pendidikan multikultural merupakan sebuah filosofi yang menekankan pada makna penting legitimasi dan vitalitas keragaman etnik dan budaya dalam kehidupan individu, kelompok maupun bangsa.

2. Pendidikan multikultural menginstitusi yang didasarkan pada prinsip-prinsipprinsip persamaan (equality), saling menghormati, menerima, memahami, dan adanya komitmen moral untuk sebuah keadilan sosial.

3. Pendidikan multikultural sebuah pendekatan pengajaran dan pembelajaran yang didasarkan atas nilai-nilai demokrasi yang mnedorong berkembangnya pluralisme budaya dan hampir seluruh bentuk komprehensifnya. Pendidikan multikultural merupakan sebuah komitmen untuk meraih persamaan pendidikan, mengembangkan kurikulum yang menumbuhkan pemahaman tentang kelompok-kelompok etnik dan memberangus praktek-praktek penindasan.

4. Pendidikan multikultural merupakan reformasi sekolah yang komprehensif dan pendidikan dasar untuk semua peserta didik yang menentang semua bentuk diskriminasi dan instruksi yang menindas dan hubungan antar personal di dalam kelas dan memberikan prinsipprinsip demokrasi keadilan sosial. 


\section{Tujuan}

Tujuan pendidikan multikultural menurut

Gorsky dalam (Ibrahim, 2013), yakni:

1. Setiap peserta didik mempunyai kesempatan untuk mengembangkan prestasi.

2. Peserta didik belajar bagaimana belajar dan berpikir kritis.

3. Mendorong peserta didik untuk mengambil peran aktif dalam pendidikan dengan menghadirkan pengalamanpengalaman dalam konteks belajar.

4. Mengakomodasikan semua gaya belajar peserta didik.

5. Mengapresiasi kontribusi dari kelompok -kelompok yang berbeda.

6. Mengembangkan sikap positif terhadap kelompok -kelompok yang berbeda.

7. Untuk menjadi waga negara yang baik di sekolah dan di masyarakat.

8. Belajar bagaimana menilai pengetahuan dari perspektif yang berbeda.

9. Untuk mengembangkan identitas etnis, nasional, dan global.

10. Mengembangkan keterampilanketerampilan mengambil keputusan dan analisis secara kritis sehingga peserta didik dapat membuat pilihan yang lebih baik dalam kehidupan sehari-hari.

\section{METODE PENELITIAN}

Metode peneltian yang digunakan dalam penelitian ini adalah metode penelitian kualitatif.Dimana data yang dikumpulkan dideskripsikan secara gamblang lewat aktivitas membaca dan mencatat (Moleong, 2002: 5).Artinya, dalam menyelesaikan tulisan ini, peneliti melalui beberapa tahap yakni mengumpulkan literatur yang bekaitan dengan judul, membaca, menganalisa, dan menggeneralisasi data-data yang dikumpulkan, sehingga pada akhirnya dapat membuat sebuah konklusi atau kesimpulan berdasarkan hasil yang diperoleh.

\section{HASIL DAN PEMBAHASAN}

\section{Kolektivitas}

Secara kodrati salah satu dimensi yang tidak bisa dipisahkan dari manusia adalah dimensi sosial. Artinya sudah terberi bahwa kodrat yang melekat pada manusia adalah hidup bersama dengan orang lain. Hal ini tidak dapat ditolak karena sesuatu yang sudah ada dalam diri manusia. Hidup bersama dengan orang lain mengandung arti bahwa ada tanggung jawab, saling memberi dan menerima, saling mendukung satu sama lain. Selain itu, juga bahwa hidup bersama dengan orang lain menuntut untuk menerima aneka perbedaanperbedaan yang ada. Menerima perbedaan berarti mengakui keberadaan atau eksistensi yang lain. Dengan demikian, tercipta kedamaian dalam kebersamaan.

Kolektivitas kelompok-kelompok masyarakat Indonesia bersifat majemuk. Indonesia memiliki 656 suku bangsa, dengan 300 jenis bahasa lokal, berdasarkan wilayah atau lingkungan hidup, beraneka pula mata pencaharian kelompok-kelompok masyarakat tersebut (Juharman, dkk. 2014: 78). James A. Banks dalam (Sulalah, 2011: 47) menjelaskan bahwa pendidikan multikultural dimaknai sebagai sebagai sebuah konsep, ide, atau falsafah, yang merupakan suatu rangkaian kepercayaan (set of believe) dan penjelasan untuk mengakui, dan menilai pentingnya keragaman budaya di dalam membentuk gaya hidup, pengalaman sosial, identitas pribadi, kesempatan-kesempatan pendidikan dari individu maupun kelompok. Dengan mengakui perbedaan-perbedaan dalam pluralitas berarti ada kesiapan untuk membangun hubungan atau konektivitas dengan orang lain.

\section{Konektivitas}

Konektivitas merupakan suatu sikap di mana orang bersedia untuk membangun hubungan dengan orang lain. Hal ini berarti bahwa membangun konektivitas berarti orang mau berinteraksi, berkomunikasi, dan berkooperasi dengan orang lain. Konsep konektivitas sebenarnya menjelaskan sikap untuk saling berhubungan dan mengembangkan suatu kehidupan yang bermakna (Bdk. We'u, 2016: 67).

Kiai Sholeh dalam (Sulalah, 2011: 59) menjelaskan bahwa pendidikan multukultural membantu manusia untuk saling mengenal (ta'aruf) yang akan melahirkan sikap saling mengerti. Jika hubungan antar sesama didasari adanya saling mengerti atau saling memahami (mutual understanding), maka akan melahirkan sikap saling menghargai (mutual respect).

\section{Respeksivitas}

Respeksivitas merupakan sebuah tindakan etik yang menunjukkan bahwa manusia adalah makluk yang berakal budi (ens rationale). Dengan akal budi manusia dapat membentuk 
sikap moral yang baik terhadap sesamanya dengan sikap saling menghormati satu sama lain. Artinya, sebagai manusia setiap individu pasti memiliki sifat santun yang dapat ditunjukkan kepada orang lain atau sikap saling menghormati. Oleh karena itu, sebelum menuntut orang lain untuk menghormati diri pribadi, sikap penting yang harus ditanamkan adalah menghormati diri sendiri. Dengan menghormati diri sendiri maka menjadi tahu menghormati orang lain. Kehidupan yang aman akan dijunjung tinggi apabila ada sikap saling menghormati atau semangat respeksivitas yang tinggi terhadap orang lain (mutual respect).

Pendidikan multikutural harus terus mengakar dalam diri pimpinan pendidikan dengan menganggap manusia harus terus berbuat baik kepada sesama di muka bumi ini, untuk saling mencintai, saling mengasihi satu sama lain. Hal ini akan berhasil bilamana setiap pimpinan pendidikan memahami bahwa pada hakikatnya semua manusia mempunyai kebutuhan yang sama, yaitu butuh akan pengakuan, butuh akan penghormatan (Sulalah, 2011: 124).

\section{Inklusivitas}

Inklusif adalah sikap terbuka untuk menerima orang lainsebagai saudara. Implementasi dari sikap ini adalah terbuka untuk ada dan hidup bersama dengan orang lain (kolektif), terutama terbuka untuk membangun hubungan (konektif) untuk menghormati orang lain, terbuka untuk memberi dan menerima, terbuka untuk dialog, terbuka untuk kerja sama dan sebagainya. Gereja katolik menerbitkan "sikap Gereja terhadap para penganut agamaagama lain: Refleksi dan orientasi tentang dialog dan misi" yang menyajikan suatu definisi yang luas tentang dialog antar agama. Dialog antar agama bukan cuma berarti diskusi, tetapi juga mencakup segala relasi antaragama yang positif dan konstruktif dengan pribadi dan jemaat dari iman kepercayaan yang lainterarah pada saling memahami, dan saling memperkaya (a3). Perhatian utamanya adalah "saling hubung yang tetap terjalin antara dialog dan misi" (a5), dalam (Kirchberger, 2004: 55-56).

Inklusivitas merupakan sikap terbuka untuk bergaul dengan orang lain atau kelompokkelompok lain. Orang yang terbuka adalah orang yang dekat dengan orang lain atau kelompokkelompok lain (Bdk. Sumartana, 2001: 262). Eksistensi pendidikan multikultural akan berpotensi menghidupkan kembali suasana dialogis dalam komunitas lembaga pendidikan keagamaan. Padahal apabila diamati akhir-akhir ini, lembaga pendidikan keagamaan seperti pesantren dan seminari, sejak berdirinya senantiasa berupaya berdialog dengan lingkungan masyarakat sekitarnya. Keberadaan yang mengakar di tengah-tengah masyarakat menjadikan lembaga pendidikan keagamaan tersebut terkesan tidak terisolir apalagi eksklusif (Sulalah, 2011: 69).

\section{Universalitas}

Universalitas adalah sikap menerima semua hal yang bersifat umum atau mondial. Sikap-sikap itu antara lain, menerima semua manusia yang ada tanpa diskriminasi, dalam hal suku, agama, bahasa daerah, budaya, pekerjaan, tingkat pendidikan dan status sosial. Siap menjujung tinggi nilai-nilai kehidupan yang bersifat universal seperti keimanan, tanggung jawab, keadilan, kebenaran, kejujuran, kerja keras, kerja sama, loyalitas, dedikasi, keberanian, kedisiplinan, kesetaraan dan sebagainya.

Realitas ini merupakan nilai tambah yang amat berharga karena merupakan daya dukung dan kelanjutan dari pengembangan pendidikan multikultural (Sulalah, 2011: 135). Hal ini didikung oleh Kebung (2006), dengan mengatakan bahwa manusia adalah makluk sosial yang memberikan perhatian kepada kepentingan orang lain. Dalam diri manusia ditemukan kebenaran ungkapan filsuf eksistensialis Prancis Gabriel Marcel "esse co esse est" yakn ada sebagai manusia selalu berarti "ada bersama". Manusia adalah makluk yang akan sadar diri sebagai satu dari sekian banyak makluk lain. Manusia juga mengarahkan perhatiannya kepada dunia universal.

\section{KESIMPULAN}

Masyarakat Indonesia mesti menerima kepluralitasan ini sebagai fakta sosial yang dapat membangun semangat persaudaraan dan semangat kebangsaan yang tinggi.Karena kepluralitasan merupakan aset bangsa, yang mesti terus dihargai dan dijunjung tinggi.Dengan demikian, sikap respeksivitas mutlak diperlukan untuk mewujudkan Indonesia aman dan damai.Kedamaian menjadi dambaan semua insan untuk menikmati hidup yang adalah anugerah Tuhan yang mesti terus dipupuk dan dikembangkan agar kehidupan Negara Kesatuan Republik Indonesia tercinta ini menjadi negara yang cinta damai. 


\section{SARAN}

Para stakeholders memiliki tanggung jawab besar dalam rangka memberi pemahaman kepada masyarakat agar masyarakat mengerti dan mau menerima pluralitas ini sebagai bagian yang tidak terpisahkan dari kehidupan ini, karena negara ini dibangun atas dasar semangat bhineka tunggal ika.

\section{DAFTAR RUJUKAN}

Ibrahim, Rustam. Pendidikan Multikultural: Pengertian, Prinsip, dan Relevansinya dengan Tujuan Pendidikan Islam. Dalam Jurnal ADDIN, Vol. 7. No. 1.Februari 2013. Jurnal Universitas Nahdatul Ulama (UNU) Surakarta, Jawa Tengah (Media Online) Diakses 05 September 2018.

Jurahman, Yohanes. B. 2014. Pengantar Ilmu Sosial Budaya Dasar.Salatiga. Widya Sari Press.

Kebung, Konrad. 2006. Esai tentang Manusia. Volume 1 Manusia dan Diri yang Utuh.Ende. Nusa Indah.

Kirchberger, Georg. (Editor). 2004. Misi Evangelisasi Penghayatan Iman. Maumere: Ledalero.

Moleong, Lexy J. 2002. Metodologi Penelitian Kualitatif. Bandung: Remaja Rosdakarya

Sulalah.2011. Pendidikan Multikultural. Malang. UIN-Maliki Press.

Sumartana, dkk. 2001. Pluralisme, Konflik, dan Pendidikan Agama di Indonesia. Yogyakarta. Institut Dian/Interfidei.

We'u. Gregorius. 2016. Penelitian Tindakan Kelas. Ende: Nusa Indah. 